\title{
Global longitudinal strain and red cell distribution width in patients with mild, moderate and severe aortic stenosis, preserved left ventricular ejection fraction and unestablished coronary artery diseases: improving prediction of left ventricle dysfunction with a simple test
}

\author{
(DIvana Jurin', \\ (D)Dubravka Šušnjar' \\ (D)Josip Varvodić', \\ DIgor Rudež', \\ (DFrane Paić², \\ DIrzal Hadžibegović ${ }^{*}$ \\ 'University Hospital Dubrava, \\ Zagreb, Croatia \\ 2University of Zagreb School \\ of Medicine, Zagreb, Croatia
}

RECEIVED:

May 1, 2018

ACCEPTED:

May 10, 2018

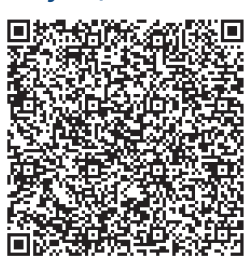

$\square$ Cardiologia Croatica 2018:13(5-6):200
KEYWORDS: global longitudinal strain, aortic stenosis, red cell distribution width CITATION: Cardiol Croat. 2018;13(5-6):200. | https://doi.org/10.15836/ccar2018.200

*ADDRESS FOR CORRESPONDENCE: Irzal Hadžibegović, Klinička bolnica Dubrava, Avenija Gojka Šuška 6, HR-10000 Zagreb, Croatia. / E-mail: irzalh@gmail.com

ORCID: Ivana Jurin, https://orcid.org/0000-0002-2637-9691 • Dubravka Šušnjar, https://orcid.org/0000-0002-9644-9739 Josip Varvodić, https://orcid.org/0000-0001-6602-699X • Igor Rudež, https://orcid.org/0000-0002-7735-6721 Frane Paić, https://orcid.org/0000-0001-9688-8582 • Irzal Hadžibegović, https://orcid.org/0000-0002-3768-9134

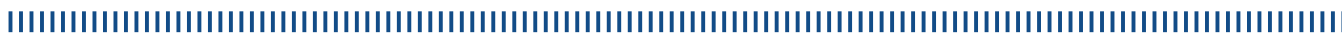

Background: Patients with preserved left ventricular ejection fraction (EF) and aortic stenosis have often increased global longitudinal strain as a sign of intrinsic left ventricular impairment. Heart failure due to left ventricular deformation is also shown to be predicted with simple blood count test like red cell distribution width (RDW). We evaluated the correlation of GLS and RDW patients with different severity stage of aortic stenosis and signs of left ventricular strain.

Methods: We recorded relevant clinical, laboratory, and echocardiographic parameters, and measured global longitudinal strain (GLS) in 83 patients with EF > 45\% and mild, moderate, and severe aortic stenosis (AS) in whom coronary artery disease was previously excluded. GLS was obtained using 2D speckle tracking echocardiography. RDW was easily obtained from full blood count that is routinely measured.

Results: Mean velocity and aortic valve area was $2.73 \mathrm{~m} / \mathrm{s}$ and $1.72 \mathrm{~cm}^{2}, 3.37 \mathrm{~m} / \mathrm{s}$ and 1,33 $\mathrm{cm}^{2}$, and 4.62 $\mathrm{m} / \mathrm{s}$ and $0.74 \mathrm{~cm}^{2}$ in patients with mild, moderate and severe AS, respectively. Mean GLS was $-18.82 \%$, $-17.7 \%$ and $-16.85 \%$ in patients with mild, moderate and severe AS, and did not differ significantly. Patients with severe aortic stenosis had significantly higher left ventricular mass index and NT-pro BNP levels compared to patients with mild and moderate AS $\left(186.66 \mathrm{~g} / \mathrm{m}^{2} \mathrm{vs} 133.57\right.$ and $169.57 \mathrm{~g} / \mathrm{m}^{2}$, and $2644.69 \mathrm{pg} / \mathrm{ml}$ vs $312.71 \mathrm{vs} 403.2 \mathrm{pg} / \mathrm{ml}$, respectively). Among patients with mild aortic stenosis regression analysis showed significant positive correlation of GLS with RDW (beta 0.590, R square 0.34, $\mathrm{p}=0.005$ ). That correlation was not confirmed for GLS and NT-pro BNP.

Conclusion: GLS did not differ significantly among patients with different severity of AS, although patients with severe AS had highest values of GLS. Among patients with moderate AS, RDW showed to be a good predictor of impaired left ventricular function measured by GLS, and therefore it could be further evaluated as a tool in early selection for treatment of patients with moderate AS, preserved EF and no coronary artery disease. 